Original Article

\title{
UTILIZATION OF MATERNAL HEALTH CARE SERVICES IN SLUM AREAS OF DHAKA CITY, BANGLADESH
}

\author{
Housne Ara Begum ${ }^{1}$, Nilufar Yeasmin Nili², Amir Mohammad Sayem ${ }^{3}$ \\ ${ }^{1}$ Institute of Health Economics, University of Dhaka; ${ }^{2}$ Directorate General of Health Services (DGHS), \\ Dhaka, Bangladesh; ${ }^{3}$ Department of Population Sciences, University of Dhaka, Dhaka, Bangladesh
}

\begin{abstract}
Bangladesh has one of the highest maternal mortality rates (MMR) in the world. The estimated lifetime risk of dying from pregnancy and childbirth related causes in Bangladesh is about 100 times higher compare to developed countries. However, utilization of maternal health care services (MHCS) is notably low. This study examines the socio-economic determinants of utilization of MHCS in some slum areas of Dhaka city. The overall utilization was $86.3 \%$ of women; however, utilization of different sorts of MHCS was very low, i.e., the mean utilization was found to be 2.25 out of 5 MHCS. Indicator wise, ANC, TT, institutional delivery, delivery assistance by health professional and PNC were received by $61.3 \%, 80.4 \%, 12.6 \%, 33.2 \%$ and $55.4 \%$ of women respectively. Variation was observed with different socio-economic variables. Multiple regression model could explain $38 \%$ of variance $(\mathrm{P}<0.001)$. Among the significant determinants, order of last birth negatively explained the most variance $(15.2 \%)$. Similarly, distance between home and clinic was found to affect the utilization negatively. Besides, some respondents' socio economic variables had a significant positive effect on MHCS utilization. To reduce maternal mortality in disadvantaged women in slum areas, this study might suggest a few pointers while considering formulation of policies and planning.
\end{abstract}

Ibrahim Med. Coll. J. 2010; 4(2): 44-48

Keywords: determinants, utilization, maternal health care, service, slum areas

\section{Introduction}

Over half a million women from the developing world die each year of causes related to pregnancy and childbirth. ${ }^{1}$ There are about 500 maternal deaths for every 100,000 live births, and around 10 per cent of the pregnancies are at high-risk. ${ }^{2}$ Maternal mortality is on average 18 times higher in developing countries compared to developed countries. ${ }^{3}$ In addition to the number of deaths in each year, over 50 million women suffer from maternal morbidity due to acute complications from pregnancy. ${ }^{4}$

Despite the presence of strategic and programmatic initiatives in order to reduce maternal and child health, maternal mortality and child mortality and morbidity continue to be high. Bangladesh has one of the highest maternal mortality rates (MMR) in the world, i.e. 3/
1000 live births. ${ }^{5}$ The tragic consequence of these deaths is that about $75 \%$ of the babies born to these women also die within the first week of their lives. On the other hand, infant and child mortality are respectively 52 per 1000 live birth and 14 per 1000 children. ${ }^{6}$

The reason of such maternal and child health scenario in Bangladesh is mainly due to several factors, an important one being non-utilization or under-utilization of maternal health-care services, especially amongst the rural poor and urban slum population due to either lack of awareness or access to health-care services. With respect to such reality it is very crucial to understand the factors that determine the use of such service in order to increase the further utilization of

Address for Correspondence:

Dr. Housne Ara Begum, Associate Professor, Institute of Health Economics, University of Dhaka, Dhaka-1000, Bangladesh 
MHCS among the poor women. However, studies on these are almost absent or very limited. This study was carried out to examine the socio-economic, demographic and cultural factors affecting the utilization of MHCS among women aged 15-49 years.

\section{Methods and Materials}

The data used in this study were collected from three randomly selected slum dwelling women of reproductive age through a semi structured survey questionnaire which included the socioeconomic, demographic and cultural characteristics of respondents as well as the family, and utilization of maternal health care services in their last pregnancy. The slums were identified applying the cluster sampling technique. From the three slums, 540 women were successfully interviewed. Simple linear regression analysis was considered at multivariate level in order to identify the factors affecting the utilization of maternal health services. In this regard, the following equation was used to estimate the regression coefficients:

$\mathrm{Y}=\mathrm{a}+\mathrm{b}_{1} * \mathrm{X}_{1} \ldots \ldots \ldots \ldots+\mathrm{b}_{\mathrm{k}} * \mathrm{X}_{\mathrm{k}}+\mathrm{e}$

Where, $\mathrm{Y}=$ dependent variable, $\mathrm{a}=$ constant, $\mathrm{b}=$ the regression coefficient, $\mathrm{X}=$ independent variables of the model, $\mathrm{K}=$ end number of the series, $\mathrm{e}=$ error term.

\section{Results}

\section{Utilization of Maternal Health Care Services}

Utilization of the number of services by the women in general was lower than expected. On average, women utilized 2.25 MHCS with standard deviation 1.46. Among 86.3\% women who utilized MHCS, $21.1 \%, 17.8 \%$ and $29.4 \%$ of them utilized respectively 1,2 and 3 MHCS while only $9.8 \%$ and $8.1 \%$ women respectively utilized 4 and 5 MCHS.

A pattern of MHCS utilization was observed with the age of the women in the slum areas; the older the age, the less likely was the likelihood that they utilized the MHCS (Figure 1). On average, women aged $<20$ and 20-29 utilized respectively 2.53 and 2.58 MHCS. On the other hand, 2.22 and 1.42 MHCS were respectively utilized by women aged 30-39 and 40-49 years.

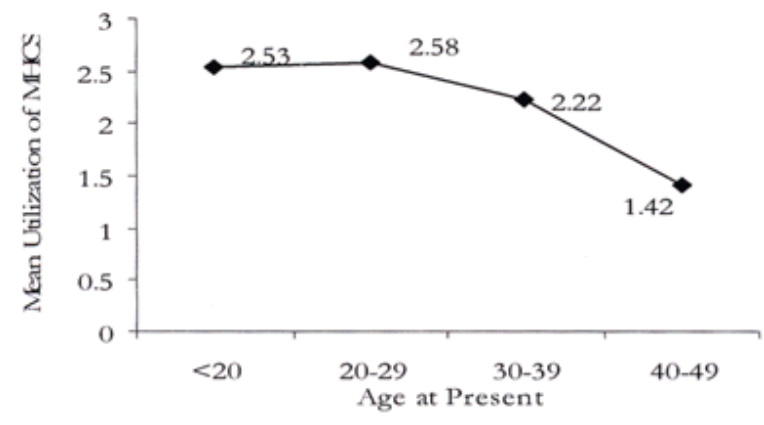

Fig-1. Utilization of MHCS by respondent's age at present

The indicators of MHCS were ANC, TT, place of delivery, assisted delivery and PNC. Specifically, ANC, TT and PNC service utilization were higher than other MHCS. More than two-fifth women utilized 3 visits during their last pregnancy while $80.4 \%$ and $55.4 \%$ women respectively utilized $\mathrm{TT}$ and PNC services (Table 1). Home delivery was done by $87.4 \%$ of women against $12.6 \%$ institutional delivery while $66.8 \%$ women were delivered by traditional birth attendants against 33.2 by a medically trained professional.

\section{Correlates of Utilization of Maternal Health Care Services}

The utilization of maternal health care services was found to differ with varying socio-economic, demographic and cultural characteristics and with

Table-1: The distribution of indicators based utilization of maternal health care services

\begin{tabular}{ll|r|r}
\hline MHCS Indicators Categories & N & $\%$ \\
\hline Number of ANC & None & 209 & 38.7 \\
& $1-2$ & 83 & 15.4 \\
& $>=3$ & 248 & 45.9 \\
Receive of TT & Yes & 434 & 80.4 \\
& No & 106 & 19.6 \\
Place of Delivery & Home & 472 & 87.4 \\
& Institution & 68 & 12.6 \\
Delivery Assistant & Medically trained & 139 & 33.2 \\
& or Professional & & \\
& Traditional dai (TBA) & 361 & 66.8 \\
Receive of PNC & Yes & 299 & 55.4 \\
& No & 241 & 44.6 \\
\hline
\end{tabular}


different categories of each independent variable (Table 2). Women's education with moderate correlation (0.343) was found statistically significant at $\mathrm{P}<0.05$. Women with primary and primary + education were found to utilize more of the MHCS than women with no education. On average, 2.53 and 3.14 MHCS were respectively used by women with primary and more than primary education against use of 1.77 MHCS by women with no education. Similar to women's education, a significant positive relationship was observed by background schooling, respondent's autonomy, positive attitude towards MHCS, male participation in maternity care, mass media exposure, consumable goods, monthly family income and husband's monthly income indicating a higher utilization with higher levels in such characteristics.

Besides, the order of last birth had a significant negative association with utilization of MHCS. On average, women who had given only one birth utilized 2.92 MHCS which almost gradually decreased to around 1.72 among women who had given birth to more than 6 children. Almost similarly, distance form home to clinic and respondent's age at last birth had significant association with utilization of MHCS suggesting that women whose households were far away from clinic and who were older were more likely to utilize MHCS less than those women whose household was nearer to the clinics and were at a younger age.

\section{Determinants of Utilization of MHCS}

Simple linear regression technique was used to examine the determinants of utilization of maternal health care services. Before running regression model, assumptions of linear regression like interval level of measurement, linear relationship and nomulticolineanrity were met. All the variables significant at bi-variate analysis were included into the regression models; however, at multivariate analysis all the variables were not found to have significant explanatory power on dependent variables mainly due to the removal of effect by other variables as stepwise method was used.

The overall regression model explained $38.0 \%$ (Adjusted R Square) of variance with $\mathrm{P}<0.001$ in utilization of MHCS (Table 3). The most explanatory variable was order of the last birth which alone explained $15.2 \%$ variance $(\mathrm{P}<0.001)$ indicating that women's higher birth order of the last child were less likely to utilize MHCS in slum areas. With similar direction to order of last birth, distance between home and clinic and age at last birth respectively explained $3.0 \%$ and $0.6 \%$ of variance.

Consumable goods was found to have a positive influence on the dependent variable explaining $7.5 \%$ of variance which is the second most significant variable indicating that women with higher number of consumable goods were more likely to utilize MHCS. Among others, respondents' autonomy, background schooling, male participation, monthly family income, husband's monthly income, mass media exposure, and respondents' attitude towards MHCS respectively explained $5.9 \%, 2.2 \%, 1.4 \%, 1.0 \%$, $1.0 \%, 0.7 \%$ and $0.7 \%$ of the variance.

\section{Discussion}

Over all, the level of the utilization of maternal health care services was no satisfactory in the slum areas. On average, women received 2.25 MHCS. Due to the greater confidence and experience of the older and higher parity women together with greater responsibilities within the household and for child care, these women were more likely to utilize maternal health care services. ${ }^{7}$ However, in this study, the findings were opposite. Similar findings were also found in other studies..$^{\mathbf{8 , 9 , 1 0}}$

As hypothesized in this study, consumer durables had a significant positive influence on utilization of MHCS. Others studies also found positive influence of MHCS with socio-economic status. ${ }^{11-16}$ Similar to consumer durables higher utilization was also found to be positively related with higher family income which is also consistent with other studies..$^{\mathbf{8 , 1 4 - 1 8}}$

Women having a longer distance from home to clinic utilized less MHCS than women with shorter distance. This is similar to many other studies. ${ }^{19-26}$ This may be because poor road conditions and congested houses can make it extremely difficult for women to reach even relatively nearby facilities. In a study conducted in Tanzania, it was found that women who gave birth at home actually intended to deliver at a health facility but could not do so due to distance and lack of transportation. ${ }^{27}$ 
Table-2: The determinants of utilization of maternal health care services in slum areas

\begin{tabular}{|c|c|c|c|c|c|}
\hline \multirow{2}{*}{ Variables } & \multicolumn{2}{|c|}{ Unstandardized Coefficients } & \multirow{2}{*}{$\begin{array}{c}\text { Standardized Coefficients } \\
\text { Beta }\end{array}$} & \multirow{2}{*}{$\begin{array}{c}T \\
\text { Values }\end{array}$} & \multirow{2}{*}{$\begin{array}{l}\text { R Square } \\
\text { Change }\end{array}$} \\
\hline & B & Std. Error & & & \\
\hline (Constant) & 1.221 & .277 & & $4.412 * * *$ & \\
\hline Order of Last Birth & -.347 & .044 & -.369 & $-7.803 * * *$ & .152 \\
\hline Consumerable Goods & .076 & .030 & .123 & $2.564^{*}$ & .075 \\
\hline Respondent's Autonomy & .140 & .030 & .173 & $4.676^{* * *}$ & .059 \\
\hline Distance between Home and Clinic & -.104 & .021 & -.187 & $-4.910 * * *$ & .030 \\
\hline Mean School & .022 & .006 & .148 & $3.620 * * *$ & .022 \\
\hline Male Participation & .116 & .034 & .123 & $3.420 * *$ & .014 \\
\hline Monthly Family Income & .000 & .000 & .370 & $3.931 * * *$ & .010 \\
\hline Husband's Monthly Income & .000 & .000 & .275 & $3.114 * *$ & .010 \\
\hline Mass Media Exposure & .005 & .002 & .106 & $2.636^{* *}$ & .007 \\
\hline Respondent's Attitude & .066 & .025 & .099 & $2.644^{* *}$ & .007 \\
\hline Respondent's age at last birth & .025 & .011 & .107 & $2.235^{*}$ & .006 \\
\hline
\end{tabular}

Multiple $R=0.627 ; \quad R$ Square $=0.393 ; \quad$ Adjusted $R$ Square $=0.380 ; \quad F$-Value $=31.035^{* * * *}$

$d f=11$ and $528 ; \quad * * * P<0.001, * * P<0.01$ and $* P<0.05$

Women who had higher schooling were more likely to utilize maternal health care services. Education of husband and in-laws also provide knowledge based surroundings by which women may exercise the freedom and autonomy towards reproductive choices and practices.

Mass media increases awareness about innovations, and fosters inter-personnel communication, which could facilitate behavioural changes allowing for the adoption of new/different behaviours. ${ }^{28-29}$ Consistently, mass media exposure had significant positive impact on maternal health care services utilization. Women with higher positive attitude towards maternal health care services were found to utilize MHCS more than that of women with negative attitude. This may be because positive attitude diverts them from traditional way of care seeking such as from traditional birth attendant and/or relatives. Women who gave birth at higher ages were found to utilize MHCS more compared to women with lower age at last birth. Most probably this was because the former group were more experienced on complications due to pregnancy and were more inclined to seek service from health professional.

\section{Conclusion}

The reduction of maternal and child mortality and morbidity mostly depends on the utilization of maternal health care services from pregnancy to after 42 days of delivery. However, the utilization of such care services was not satisfactory among women in slum areas of Dhaka city. With differing socio-economic and demographic characteristics of women the variation in utilization of such care was found. Thus, it may be concluded that such determinants in regard to increase in the utilization of MHCS and reducing maternal and child mortality and morbidity may be very crucial.

\section{Acknowledgement}

We acknowledge the financial support provided by United Nations Population Fund (UNFPA) for conducting this research.

\section{References}

1. Pregnancy exposes women in poor states to 200 -fold risk of death, compared with rich ones, says WHO. Populi 2000; 27: 4.

2. The state of world population: United Nations Population Fund, New York, 1995.

3. Revised 1990 estimates of maternal mortality: a new approach by WHO and UNICEF, World Health Organization, Geneva, 1996.

4. The Progress of Nations, UNICEF: New York, 1996. 
5. Bangladesh Bureau of Statistics. Statistical Pocket Book, Ministry of Planning, Government of Bangladesh, Dhaka, 2002.

6. Bangladesh Demographic and Health Survey 2007.

7. Kwast BE, Liff JM. Factors associated with maternal mortality in Addis Ababa, Ethiopia, Int J Epidem 1988; 17: 115-121.

8. Elo TI. Utilization of maternal health-care services in Peru: the role of women's education, Heal Trans Rev 1992; 2: 49-69.

9. Bhatia JC, Cleland J. Determinants of maternal care in a region of South India, Heal Trans Rev 1995; 2: 127-142.

10. Wong EL, Popkin BM, Gullkey DK, Akin JS. Accessibility, quality of care and prenatal care use in the Philippines, Soc Sci Med 1987; 24: 927-944.

11. Leslie J, Gupta GR. Utilization of formal services for maternal nutrition and health care. International Center for Research on Women, Washington, DC, 1989.

12. Addai I. Demographic and socio-cultural factors influencing use of maternal health services in Ghana, African J Repro Heal 1998; 2: 73-80.

13. Addai I. Determinants of use of maternal-child health services in rural Ghana, J Biosoc Sci 2000; 32: 1-15.

14. Fosu GB. Childhood morbidity and health services utilization: cross-national comparisons of user-related factors from DHS data, Soc Sci Med 1994; 38: 1209-1220.

15. Uchudi JM. Covariates of child mortality in Mail: does the health seeking behavior of the mother matter? J Biosoc Sci 2001; 33: 33-54.

16. Navaneetham K., Dharmalingam A. Utilization of maternal health care services in Southern India, Soc Sci Med 2002; 55: 1849-1869.

17. Fatimi Z, Avan I. Demographic, socio-economic and environmental determinants of utilization of antenatal care in rural setting of Sindh, Pakistan, J Pak Med Assoc 2002; 52: 138-142.

18. Rani M, Bonu S. Rural Indian women's care seeking behavior and choice of provider for gynecological symptoms, Stud Fam Plann 2003; 34: 173-185.
19. Tinker AG. Improving women's health in Pakistan. Health, nutrition and population working paper series. Human Development Network, World Bank 1998.

20. Alix-Dancer P. Access to health care in developing countries. In: Developing countries, society and technology. Stockholm: Royal Institute of Technology (KTH), 2003.

21. Princy Yesudian P. Impact of Women's Empowerment, Autonomy and Attitude on Maternal Health Care Utilization in India, Global Forum for Health Research, Mexico City, November 2004.

22. Rahaman MM, Aziz KM, Munshi MH, Patwari Y, Rahman M.A diarrhoea clinic in rural Bangladesh: influence of distance, age and sex on attendance and diarrheal mortality, Am J Pub Heal 1982; 72: 11241128.

23. Stock R. Distance and utilization of health facilities in rural Nigeria, Soc Sci Med 1983; 17: 63-570.

24. Abbas AA, Walkern GJA. Determinants of the utilization of maternal and child health services in Jordan, Int J Epidem 1986; 15: 404-407.

25. Airey T. The impact of road construction on hospital in-patient catchment in the Meru district of Keneya, Soc Sci Med 1989; 29: 95-105.

26. Paul BK. Health service resources as determinants of infant death in rural Bangladesh: an empirical study, Soc Sci Med 1991; 32: 43-49.

27. Bicego G, Curtis S, Raggers H, Kapiga S, Ngallaba S. Sumve survey on adult and childhood mortality, Tanzania, 1995: in-depth study on estimating adult and childhood mortality in settings of high adult mortality. Macro International, Demographic and Health Surveys (DHS) 1997; Calverton, Maryland.

28. Ahmed SM, Adams AM, Chowdhury M, Bhuiya A. Gender, socioeconomic development and health seeking behavior in Bangladesh, Soc Sci Med 2000; 51: 361-371.

29. Valente TW, Poppe PR, Merritt AP. Mass-mediagenerated inter-personnel communication as sources of information about family planning, J Heal Commun 1961; 3: 247-265. 